\title{
Aneurysm of The Ascending Aorta in A Six Year Old Girl: Case Report
}

\author{
Lakehal Redha ${ }^{1}$, Aimer Farid ${ }^{1}$, Bouharagua Rabeh ${ }^{1}$, Cherif Samiha ${ }^{1}$, Massikh Nadjet ${ }^{1}$, \\ Aziza Baya ${ }^{1}$, Bendjaballah Soumaya ${ }^{1}$, Boukharoucha Radouane ${ }^{1}$, Brahami Abdelmallek ${ }^{1}$
}

1) Department of heart surgery, EHS Erriadh, Constantine, Algeria

\section{Introduction}

The aorta is the largest artery in the body and is the blood vessel that carries oxygen-rich blood away from the heart to all parts of the body. An aortic aneurysm is bulging out of the walls of the aorta. Aortic aneurysm is exceptional in children. It is a serious condition because of the risk of rupture requiring urgent surgery.

Diagnosing a thoracic aneurysm is difficult because often there are no symptoms, and often the condition goes undiagnosed until a rupture occurs. The diagnosis is based on the Computed tomography (CT) scan and Magnetic resonance imaging (MRI).

\section{Case}

This case is for us an opportunity to show that children are not save this disease.

We report the case of 06 years old children school girl 3 rd a sibling of four children from a non consanguineous marriage without a history who presents since some moths a turgor of jugular vein.
Physical examination without Abnormalities: Without hypermobile joints, chest deformities, long and thin fingers, kyphoscoliosis, high palate, inguinal hernias, and/or aracnodactilia.

Weight: 16kg./ Size: $117 \mathrm{~cm}$.

X ray radiograph: Showed a CTI: 0,44 with enlargement of the upper mediastinum.

Electrocardiogram: Showed regular sinus rhythm and heart rate to 80 beats per minute.

\section{Echocardiography:}

Aortic ring: $15 \mathrm{~mm}$;

Valsalva Sinus: $19 \mathrm{~mm}$;

Sinotubulaire: $17 \mathrm{~mm}$;

Ascending aorta: $50 \mathrm{~mm}$;

Left ventricle: $35 / 21 \mathrm{~mm}$;

Left atrium: $21 \mathrm{~mm}$;

EF: $71 \%$, RF: 39\%;

Systolic pulmonary artery pressure: $31 \mathrm{~mm} \mathrm{hg}$.

Please cite this article as: Redha L., Farid A., Rabeh B. et al. Aneurysm of the ascending aorta in a six year old girl: Case report. EJCM 2016; 04 (1): 24-26. Doi: 10.15511/ejcm.16.00124. 
Computed tomography (CT) angio scan: was realized showing: Fusiform aneurysm of the ascending aorta, aortic arch and descending aorta's normal caliber. Trunk innominate artery place left to return to right jugular. Right jugular vein dilated by compression of SVC. Emphysema under pleural right bubble.

The patient was opered under cardiopulmonary bypass established between the sus ascending aorta anevrysmale and right atrium. The approach was sternotomy. The per operative exploration was aortic aneurysm with normal size of sinus and aortic cusps three nonrevised. The intervention had after resection of the sus ascending aorta anevrysmale in restoration of aortic continuity by Dacron tube implanted in termino terminale.

Aortic clamping: $36 \mathrm{mn}$, duration of CPB: $58 \mathrm{mn}$. The suite immediate post operating was unfavorable with death of patient with inflammatory syndrome and vasomotor refractory shock.

\section{Comments}

The causes of ascending aortic aneurysm in children are varied. There are no real data about the incidence of aortic aneurysm in childhood. The low incidence of aortic aneurysm among children and young adults limits information about etiology, surgical indications, procedures of choice, and operative results. Aortic aneurysm can be important cause of mortality in children and adolescents.

Aortic aneurysm may be related to hereditary diseases (Marfan syndrome, Loeys -Dietz syndrome, Ehler-Danlos syndrome, Arterial Tortuosity Syndrome,

Figure 1. $X$ ray radiography sowing the enlargement of the upper mediastinum and convex right top edge.

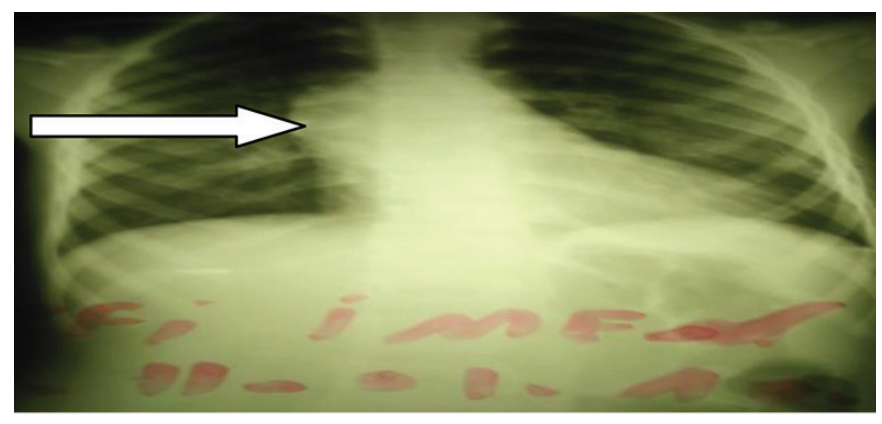

Cutis laxa syndrome, Alagille syndrome, and Noonan syndrome), or non genetic diseases (bicuspid aortic valve, coarctation of aorta, tetralogy of Fallot, and aortitis syndromes).

Among children who have aortic aneurysm, timing of surgical treatment should be weighed against life expectancy, underlying disease, the size and location of aneurysm and presence of dissection. It has been showed that beta blocker and ACE inhibitor therapy delay aortic surgery in patients with aortic an urysm related Marfan syndrome.

The indications of surgical treatment are aortic size over $5 \mathrm{~cm}$, aneurysm growth rate exceeding $1 \mathrm{~cm}$ peryear, progressive aortic insufficiency, and familial history of early aortic dissection for most of aortic aneurysm patients. However, since the risk of dissection is higher in Loeyz-Dietz syndrome, surgery is indicated even at lower diameters of the aorta.

\section{Conclusion}

Aortic aneurysm is a rare but a life threatening condition in childhood. The CTangio and MRI angio are the examinations choice in detection of aortic aneurysm. The operative indication is formal in all cases of aneurysms of the ascending aorta. Spontaneous evolution is fatal. In fact there al treatments are the surgery.

We note the severity of the inflammatory syndrome in children. It is generally related to genetic hereditary syndromes. The patients who have predisposition to aortic aneurysm should be followed-up closely.

Figure 2. Electrocardiogram showing a regular sinus rhythm.

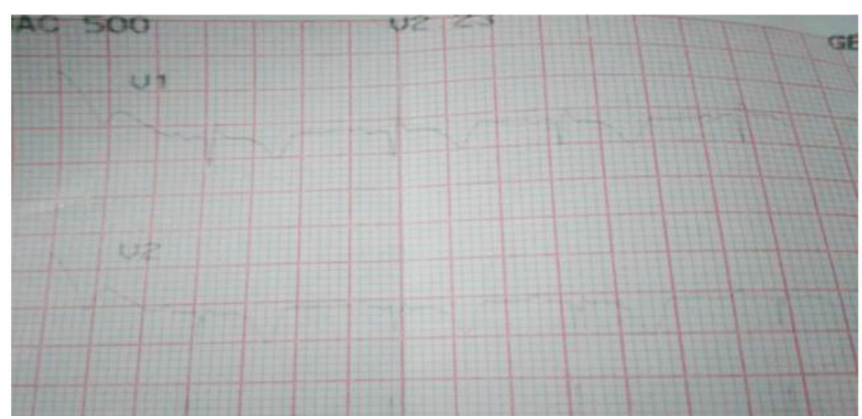


Figure 3. Echocardiography showing dilatation of ascending aorta.

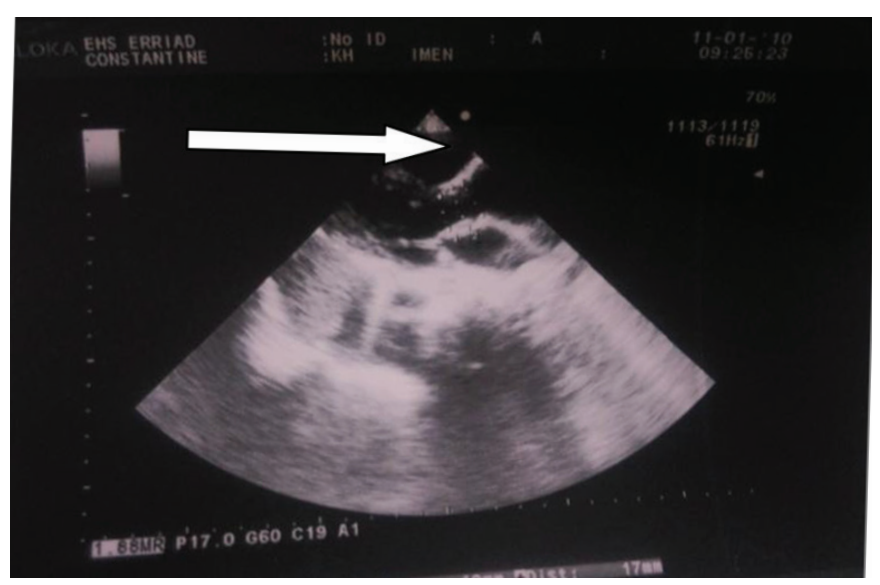

Figure 3. CTangio showing the aneurysm of the ascending aorta.

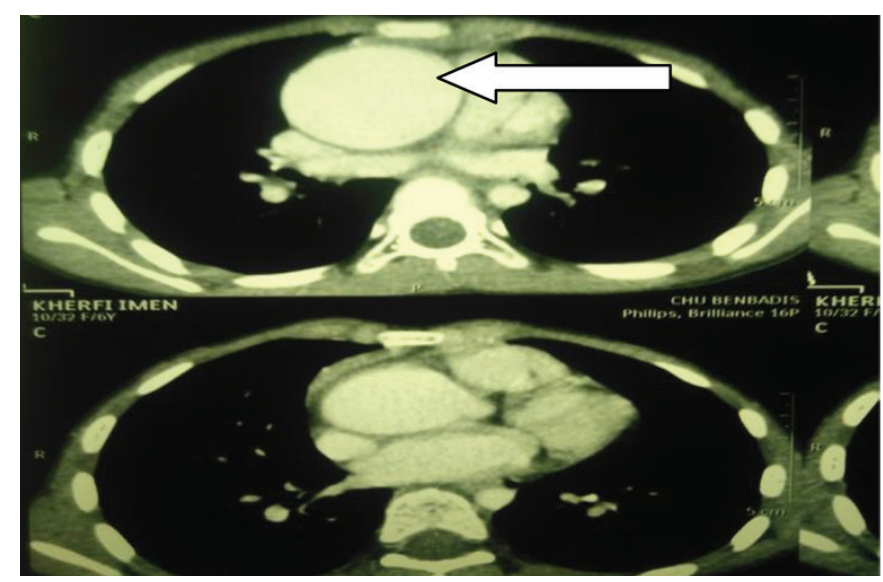

\section{References}

1. Guo D, Hasham S, Kuang S-Q, Vaughan CJ, Boerwinkle E, Chen H, Abuelo D, Dietz HC, Basson CT, Shete SS, Milewicz DM. Familial thoracic aortic aneurysms and dissections . Circulation . 2001; 103: 2461-2468.

2. Jeremy RW, Huang H, Hwa J, McCarron H, Hughes CF, Richards JG. Relation between age, arterial distensibility, and aortic dilatation in the Marfan syndrome. Am J Cardiol. 1994; 74 : 369-373.

3. Coady MA, Davies RR, Roberts M, Goldstein LJ, Rogalski MJ, Rizzo JA, Hammond GL, Kopf GS, Elefteriades JA. Familial patterns of thoracic aortic aneurysms. Arch Surg. 1999; 134: 361-367.
4. Bickerstaff LK, Pairolero PC, Hollier LH, et al. Thoracic aortic aneurysms: a population-based study. Surgery. $1982 ; 92: 1103-8$.

5. Puranik R, Chow CK, Duflou JA, Kilborn MJ, McGuire MA. Sudden death in the young. Heart Rhythm.2005;2: 1277-82.

6. Homme JL, Aubry MC, Edwards WD, et al. Surgical pathology of the ascending aorta: a clinicopathologic study of 513 cases. Am J Surg Pathol. 2006 ; 30:1159-68.

7. Nesi G, Anichini C, Tozzini S, Boddi V, Calamai G, Gori F. Pathology of the thoracic aorta: a morphologic review of 338 surgical specimens over a 7-year period. Cardiovasc Pathol. 2009 ; 18 : 134-9.

Received: $16 / 11 / 2015$

Accepted: 28/02/2016

Published: 15/03/2016

Disclosure and conflicts of interest:

Conflicts of interest were not reported.

\section{Corresponding author:}

Dr. Redha Lakehal

Mail: lakehal.redha@gmail.com 